\title{
Doutoramento "Honoris Causa" do Professor Dr. Adriano José Alves Moreira.
}

Em assembléia universitária, realizada solenemente a 12 de setembro de 1967, no salão nobre desta Faculdade, foi outorgado ao ilustre Professor Dr. Adriano José Alves Moreira o título de Doutor "Honoris Causa", pela Universidade de São Paulo.

Presidindo à Assembléia, o professor Dr. Tharcísio Damy de Sousa Santos, magnífico Reitor em exercício, designou os professôres Drs. Migucl Reale, Antônio Chaves e Soares Amorim para introduzirem no recinto o homenageado.

Após a leitura do termo de doutoramento pelo Secretário Geral da Reitoria, proferiu o elogio do doutorando o Prof. Dr. Alfredo Buzaid, diretor da Faculdade.

O novo Doutor "Honoris Causa", da Universidade de São Paulo, nasceu em Grijó-Trás-os Montes (Portugal); advogado desde 1944 é doutor em Ciências Sociais e Política Ultramarina; professor e diretor do Instituto Superior de Ciências Sociais e fundador das Universidades de Angola e Moçambique; presidente da Academia Internacional de Cultura Portuguêsa; do Centro Europeu de Informação e Documentação e da União das Comunidades de Cultura Portuguêsa; é ainda membro atuante do Instituto Híspano Luso Americano de Direito Internacional e do Instituto de Estudos Políticos de Madrid. Foi também ministro do Ultramar.

Exercendo tão altos cargos, cultor da ciência jurídica e política, publicou, entre outras obras, o Código do Tra- 
balho Rural da Africa; Direito Corporativo, Ideologias Politicas, Politica Ultramarina, Partido Português, Batalha da Esperança. No Brasil é doutor "Honoris Causa" também pela Universidade Federal do Rio de Janeiro e de Brasilia sendo, ainda; portador da Grã Cruz da Ordem do Cruzeiro do Sul.

Após a colação de grau, saudando o novo Professor "Honoris Causa", disse o Presidente da Assembléia pequena mas expressiva oração, publicada a seguir.

Oração do Professor Dr. Tharcísio Damy de Sousa Santos.

Impedido de aqui poder estar, coube-me como substituto do Magnífico Reitor em exercício, Professor Mário Guimarães Ferri, a honra insigne de presidir esta Assembléia Universitária. Essa a circunstância que, privando o M. Reitor de aqui estar, como desejara, a mim outorga o privilégio de, neste ensejo, dirigir minhas saudações a Vossa Excelência, Senhor Professor Ministro Adriano Moreira. Ao virdes a esta Faculdade, tão impregnada das mais nobres e caras tradições da gente de São Paulo neste recanto do Brasil, aqui ireis receber a comprovação - se comprovação necessária fôsse - do aprêço pela vossa obra e pelos ideais a que tendes sido sempre fiel, que testemunham vossos amigos e vossos colegas Professôres da Faculdade de Dircito, iniciadora da moção, e de tôdas as Faculdades e Institutos desta Universidade, aqui reunidos em Assembléia.

Ao vos conferir a sua mais alta láurea, quizeram a Faculdade de Direito e todo o Conselho Universitário, manifestar a consideração particular que têm pela vossa obra, pela vossa atuação de estadista, enobrecendo as tradiçôes de Portugal e marcando de forma de relêvo o progresso das províncias de ultramar. Propugnador do desenvolvimento da Cultura Portuguêsa, fostes o implantador dos Estudos Gerais Universitários das províncias de 
ultramar, poderoso instrumento de desenvolvimento e do bem-estar moral e material de suas populações. Por isso, em sua indicação unânime, a Congressão desta Faculdade, sôbre realçar os méritos de jurista renomado que ornam Vossa Excelência como Professor Universitário, dos de maior renome em Portugal, quiz ainda frisar o alto aprêço que sabe dedicais aos valores da cultura brasileira, ampliando assim e estreitando mais o intercâmbio cultural entre portuguêses e brasileiros.

Ressoam ainda por certo os écos do II Congresso das Comunidades de Cultura Portuguêsa, realizados em julho último em Luanda e em Moçambique, conclave que, estou informado, ensejou novos e proveitosos contactos em prol da consolidação dos ideais cristãos da comunidade a que nos honramos em pertencer. Essa iniciativa de Vossa Excelência, constitui um galardão a mais, a juntar-se ao já dilatado rol de serviços prestados ao vosso país e aos ideais de cultura e fraternidade.

Senhor Professor Adriano Moreira:

Ao apresentar a Vossa Excelência o tributo da sincera homenagem da Universidade de São Paulo, desejo reafirmar a convição e a certeza de que, Doutor nôvo desta Universidade, continuareis a exercer a mesma firme e denodada atuação em prol da comunidade brasileira e portuguêsa, assim servindo aos mesmos ideais, que, hoje, como sempre, nos irmanam.

\section{Oração do novo Doutor “Honoris Causa” Adriano José} Alves Moreira.

Após a saudação do Dr. Tharcisio Damy de Sousa Santos, pronunciou o novo doutor "Honoris Causa" a seguinte oração:

"Não há muitos dias, encerrou-se algures no Indico, nas águas de Moçambique, o II Congresso das Comunidades 
de Cultura Portuguêsa, ao qual tive a honra de presidir. Homens vindos de todos os continentes, portuguêses, descendentes de portuguêses, ou filiados na culturá portuguêsa, navegando em águas carregadas de história e de sentido para tôda a humanidade, meditaram em comum sôbre a importância da cultura lusíada no mundo do nosso tempo; tentaram definir e aconselhar um conjunto de procedimentos que ajudem a preservar, fortalecer e desenvolver êsse patrimônio; esforçaram-se por entender os desafios dos novos tempos que é necessário enfrentar com respostas novas; cuidaram de tornar evidentes as respostas já dadas aos problemas de sempre e que consideram um contributo valioso para o patrimônio comum de todos os povos.

"As duas centenas de congressistas, que compreendiam professôres, escritores, jornalistas, cientistas, homens de ação, sentiram-se orientados pela convicção de que, no mundo interdependente do nosso tempo, nada daquilo que afeta um povo pode ser indiferente aos outros, porque todos estão funcionalmente ligados por interêsses solidários.

"Nunca parece ter sido tão claro como hoje que, independentemente da raça, da cultura, ou da religião, todos os povos sãQ apenas parcelas do gênero humano que povoa a terra e que enfrenta os mesmos desafios mortais.

"Muitos dos que estão aqui reunidos ainda se recordarão do tempo em que os Estados Unidos da América do Norte eram divulgados como uma terra onde aconteciam coisas desproporcionadas ou divertidas que não afetavam em nada o viver qüotidiano dos nossos países; e do tempo em que a China era divulgada como um pais onde havia sempre a novidade de uma revolta de generais e o hábito das catástrofes, sem que isso tivesse reflexos noutros países.

"A curta vida da geração que está a despedir-se foi suficiente para que os primeiros se transformassem no maior poder da terra de todos os tempos e para que a 
segunda desafie o equilíbrio mundial da balança de poderes.

"Mas esta radical mutação da trama das relações internacionais, também foi acompanhada da crescente importância das pequenas e das médias potências, assim como da importância dos centros de decisão que servem valores puramente morais ou espirituais. É tão descompassado o poder dos grandes, que se alargou enormemente a margem que fica livre para a audácia dos outros.

“De tal maneira desabam à nossa volta as estruturas do passado que nunca foi mais instante a busca de uma escala de valores que iluminem os caminhos que precisamos de encontrar, neste pobre mundo, para conseguirmos aprender a viver juntos sendo diferentes.

“Quando a fome, a explosão demográfica, o poder atômico, o racismo, parecem conjugar-se para nos ameaçar com a consumação dos tempos apocalípticos, não podemos deixar de sentir a necessidade de procurar, no mundo dos valores, a luz da esperança com que o gênero humano precisa de enfrentar e dar resposta aos desafios do nosso tempo.

"Ao contrário de lastimar a multiplicação de caminhos contraditórios que se abrem à nossa frente, e ao contrário de supor que definitivamente não vale a pena lutar para evitar derramar um sangue que sempre há de ser derramado, devemos enfrentar com alegria a época em que nos aconteceu viver e participar na construção do mundo.

"Sabemos hoje que todos os esquemas políticos são instrumentais, que os impérios são transitórios, que a hierarquia das potências é efêmera, sabemos enfim que nada, salvo a cultura, tem a vocação da eternidade. Tomemos o exemplo da área de cultura lusíada onde hoje, dois poderes políticos independentes, Portugal e Brasil, sustentam uma concepção de vida com a mesma indestrutível raiz. Para além de tudo aquilo que a originalidade dos problemas fêz acrescentar às soluções regionais, o denominador comum está para sempre presente nas rela- 
ções de família, na definição das instituições básicas como o município, na afirmação da igualdade do gênero humano independentemente da etnia ou da religião, na concepção da dignidade do homem, nos estilos fundamentais de vida privada, em suma, na adopção de uma peculiar maneira de nascer, viver e morrer.

"Os valores plasmados nestes programas normativos, expressos na mesma língua, são um patrimônio comum que não pertence apenas a ambos os povos, é também parte do tesouro da humanidade.

"São valores sempre presentes na cordialidade com que se recebe o forasteiro, na humildade com que se reza por inspiração e fôrça moral, na amorosidade com que se trabalha a terra, na fraternidade com que se socorre o infortúnio dos semelhantes, na delicadeza com que se ignoram as deficiências alheias, na devoção com que se missionam as gentes, na perseverança com que se trabalha pela paz entre os homens, na coragem com que se enfrenta a luta, na galhardia com que se defronta a adversidade, na teimosia com que se encara o difícil, e até na poesia com que se desafia o impossivel.

"As nossas velhas leis, que são do Brasil e de Portugal, representam certamente a expressão mais valiosa desta experiência vivida em que baseamos a nossa busca de respostas novas para os desafios novos dos nossos tempos. Esta veneranda escola de São Francisco, onde se refletem tôdas as glórias seculares da universidade de Coimbra acrescidas da responsabilidade pela participação efetiva na construção de um mundo novo, é sem dúvida um dos pilares fundamentais desta maneira lusíada de estar no mundo. Uma maneira de estar no mundo que, como ensinou Miguel Reale, não entende o direito senão como a expressão da existência humana, como componente da projeção cultural da espécie.

"Mas justamente porque é assim, inelutàvelmente ligados os dois povos lusiadas ao patrimônio comum do passado, independentes sem dúvida, mas confrontados pela 
interdependência que é a lei do nosso tempo, responsáveis pela defesa de valores que comparticipam, porque é que não haveríamos de ser capazes de procurar respostas convergentes para os desafios do futuro? Se é tão fundamental para o-mundo que os que são diferentes aprendam a viver juntos, porque é que não hão de saber viver solidários àqueles que a história vinculou para sempre às mesmas raízes, a um patrimônio de valores indivisíveis?

"As nossas Ordenações comuns e os nossos códigos diferentes estão unidos pela mesma concepção do mundo e da vida, dęnominador de um passado igual e fontes de um futuro que pode ser solidário.

"A púrpura que consagra o mérito dos nossos trabalhos, sapientíssimos doutores, tem a côr do sangue derramado por! muitas gerações, na guerra e na paz, para definir e preservar uma maneira de estar no mundo que serve todo o gênero humano sem fazer ofensa a ninguém.

“ $E$ um verdadeiro símbolo de fidelidade a uma tarefa inacabada e sempre renovada, que não pode receber-se sem temor e hạnildade. É com essa atitude de espírito que venho aquí, heste dia maior, acatando a vossa decisão de me tornar vos\$o igual como prova da magnanimidade que acompanha sempre a sabedoria. Escutando com reverência as palavras do sábio professor doutor Alfredo Bouzaid, que encontrou na sua ilimitada generosidade modo de justificar a benevolente decisão do vosso Conselho, verdadeiramente não encontro razão mais forte para esta honra do que o meu ilimitado amor ao Brasil.

"Lidando por ofício com os problemas do tropicalismo, e procurando corresponder à tarefa modesta que me coube no campo da investigação e do ensino, nunca pude conseguir que a frieza do livre exame deixasse de ser acompanhada pelo entusiasmo e pela gratidão com que vemos a evolução e o crescimento do Brasil, na certeza de que êsse crescimento e essa fôrça servem os valores em que tenho fé e foram o credo dos nossos comuns antepassados. Todos êsses valores reunidos no respeito pela eminente 
dignidade do homem. Todos êsses valores inspirados pela convicção de que cada vida humana é um fenômeno que se não repete e não pode ser frustrada.

"Recebo a honra que me concedeis, nesta internacionalmente prestigiosa Faculdade de Direito, lembrando a mim próprio as sábias palavras de Marco Aurélio: “quantos homens, que mereceram tantas celebrações, hoje estão cobertos pelo esquecimento! E quantos homens que os celebraram estão mortos há tanto tempo!"

"Dividido sempre, pelas circunstâncias da vida, entre o pensamento e a ação, com a experiência das contingências que obrigam a diluir no fazer as dúvidas do pensar, encontrei em tôdas as atitudes, as lousas partidas, as lápides ilegiveis, os monumentos apeados, os nomes apagados, as datas esquecidas, que tudo nos lembra a contingência das pompas. Aprendí que os homens passam e só as instituições permanecem porque encarnam as idéias que nunca morrem. 